\title{
HMS Dreadnought (1906) - A Naval Revolution Misinterpreted or Mishandled?
}

\section{Angus Ross}

Loin du cuirassé révolutionnaire le plus souvent dépeint dans les comptes historiques, HMS Dreadnought était plutôt un "démonstrateur de technologie, " conçu pour présenter des qualités prévues pour mettre les cuirassés hors de jeu et non pour redonner souffle à la ligne de bataille. Son créateur, l'amiral Fisher, faisant face à des impératifs difficiles sur un plan fiscal, tactique et stratégique, a trouvé son salut dans une nouvelle stratégie navale révolutionnaire basée autour des technologies jumelles du sous-marin et du "croiseur cuirassé. " Cependant, grâce a une combinaison de caution, un curieux maltraitement des programmes de construction, et la résistance institutionnelle de la marine royale dans son ensemble, c'était tristement le Dreadnought qui a finalement prospéré, et non son cousin futuriste, le croiseur cuirassé.

"Neither do I give the Controller my detailed views on a modern cruiser, because they would simply all have a fit! And they would make it a 'misfit,' but I hope to get Sir Andrew Noble to build one on speculation at Elswick, and all the world will bid for it!" Sir John Fisher, 5 January $1904^{1}$

Few warships in history have attracted as much controversy as the first of the allbig gun battleships, HMS Dreadnought. Until recently, the conventional view was that its creators, fuelled by a "Mahanian" desire to simply build bigger and better battleships to contain, and if necessary, to destroy rival European navies, were fortunate that the technology all fell in place together at just the right time to make this ship possible. ${ }^{2}$ In

1 Written while Fisher was commander-in-chief at Portsmouth, although he had already been promised the job of first sea lord: Arthur J. Marder, ed., Fear God and Dread Nought, 3 vols. (London, 1952-9), 1: 293-4 (hereinafter referred to as FGDN). The term controller referred to the third sea lord of the Admiralty, who was responsible to the Board for the Navy's materiel and who oversaw the director of naval construction, who in turn was responsible for new designs. Sir Andrew Noble was the chairman of Armstrong \& Whitworth Company, the eventual builder of the first of the battlecruisers, HMS Invincible.

2 The term "Mahanian" refers to the writings of Captain Alfred T. Mahan, USN. Mahan appealed because he maintained that a maritime trading nation aspiring to a global market, needed to be able to exert some control over the oceans - which were effectively borderless

The Northern Mariner/le marin du nord, XX No. 2, (April 2010), 175-198 
the words of David Brown: "Dreadnought was a ship whose time had come." Having done it once, and seen its success, the next step was simply to replace the existing battlefleet with Dreadnought types and it was this activity, and its counterpart in Germany, that fuelled the ruinous naval races that did so much to de-stabilize the world in the run up to 1914. The Dreadnought has become synonymous with all that was wrong with the militarism of that age.

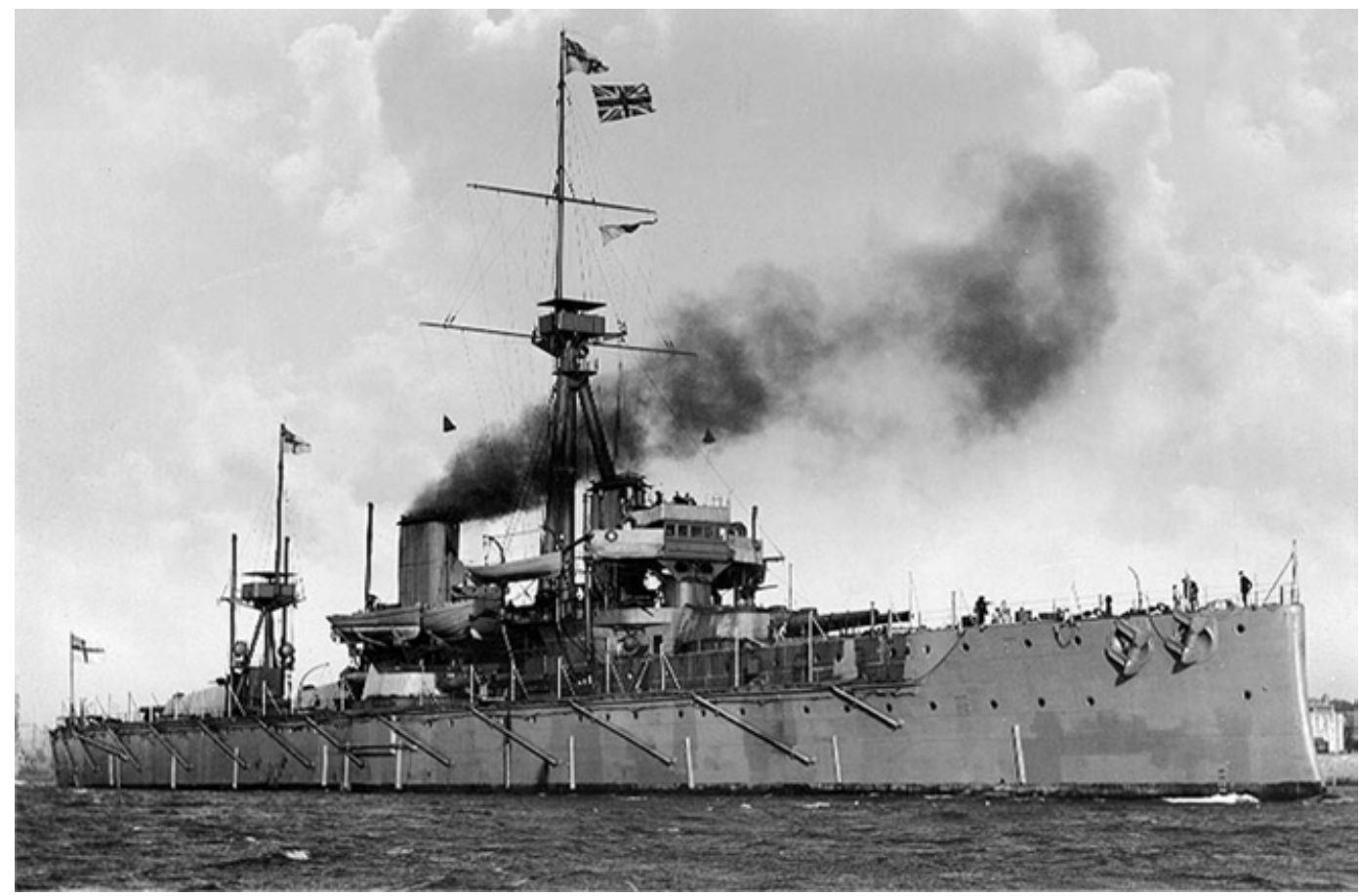

Illustration 1: HMS Dreadnought, given as 1906 but possibly later. Source: public domain.

Some of the wider socio-economic factors, however, hint at a different motivation. For one thing, Great Britain, facing the twin prospects of a slowing economy and steep increases in defence costs, was becoming desperate to make economies in its naval expenditure. This was exacerbated by the Liberal government's simultaneous

avenues for trade - in order to give the country's trade the necessary security. The best way to gain "Command of the Seas" was to develop the potential to defeat an opponent's naval forces at sea - in other words to develop a fleet of first class battleships and keep it concentrated for this eventuality - thus ensuring the necessary superiority. Since however, the oceans were borderless and assuming the need for "global influence," then this conveniently translated into a ready-made justification for a large navy. While the Royal Navy had always believed in these principles, Mahan was popular because he provided professional endorsement for what they had long believed - that the Navy should be large, and primarily composed of up-to-date battleships.

3 See D. K. Brown, Warrior to Dreadnought: Warship development, 1860-1905 (London, 1997), 180. 
desire to introduce a comprehensive and expensive program of social reform, and specifically a system of state-provided old age pensions. Second, the ship was a product of Admiral Sir John "Jackie" Fisher, the flamboyant reformer of the Edwardian Royal Navy, who had set himself the twin missions of making these necessary economies while totally overhauling the Royal Navy's modus operandi in pursuit of greater efficiency. ${ }^{4}$ While the need for savings was definitely an integral part of his plan, it is important to recognize at the outset that for Fisher the main objective was always the continuance of Great Britain's position of primacy as a maritime power. A fervent navalist with a strong sense of duty, the difference between Fisher and most of his naval colleagues was that he had realized early on that the economies being demanded were actually necessary for the nation's continuing good health. ${ }^{5}$ Thus, if maritime primacy were to be preserved, then the only dutiful way forward for the navy was to accommodate the savings by adopting a radically different vision of future naval warfare - a vision that he believed the advances in technology were on the verge of delivering. While his reforms were truly comprehensive and interdependent, the most pertinent to this discussion was a revolutionary new naval strategy based upon the twin technologies of the submarine and his "modern" cruiser. ${ }^{6}$ The latter was to be a fast and lightly armoured capital ship-sized vessel with a powerful offensive punch designed specifically for the global needs of imperial defence. ${ }^{7}$ Against this background, the building of "super-battleships" at great

$4 \quad$ Admiral Sir John Arbuthnot Fisher, (1841-1920), $1^{\text {st }}$ Baron of Kilverstone, joined the Royal Navy in 1854, served in China and Egyptian wars, in the latter in command of HMS Inflexible, the Dreadnought of her day. Promoted rear-admiral in 1890, was commander-inchief of the Mediterranean Fleet in 1900-1902 and first sea lord 1904-10.

5 A good example of how he saw the relations between the Empire, the Navy and the economy as being crucial for the health of Great Britain can be found in his "Notes by Sir John Fisher on New Proposals for the committee of seven," written in Portsmouth on 14 May 1904 and reproduced in P.K. Kemp, ed., The Papers of Admiral Sir John Fisher, vol. 1 (London: Navy Records Society, 1960), 18 (hereinafter referred to as Fisher Papers).

6 For Fisher's insistence that the whole reform package be implemented "en-bloc," see Fisher Papers, 16-21, which includes the "The Scheme! The Whole Scheme!! And Nothing But the Scheme!!" exhortation. Time and space do not permit a detailed description of all the aspects of his reforms but the main points can be summarized as follows: a) officer training and entry schemes to be consolidated so as to produce modern, technically proficient thinkers; b) old, obsolete ships to be scrapped en masse, thereby reducing operating costs, releasing manpower (for new ships) and jetty space/facilities; c) the naval reserve to be re-constituted as "nucleus crews" (2/5ths of complement) for the continuous manning of modern ships cycling through reserve status, thereby improving fleet readiness; d) the home defence (antiinvasion) alignment of the battlefleet to be replaced by using submarines and flotilla craft for sea denial, thus freeing the capital ships for global trade protection; e) the development of new classes of armoured cruisers to man these "flying squadrons" stationed at Britain's key points of interest around the world; finally f) these squadrons were to be controlled by a revolutionary new wireless link "the war room system" to the planners in Whitehall.

7 The term "battlecruiser" which is used in this article actually comes from a later period when it was recognized that these vessels would have to serve in the battleline. In this period they tended to be called "armoured cruisers," but in order to distinguish them from this earlier type of ship that was still being built at the time, the author has used the terms "battlecruiser" 
expense and seemingly for the sake of perpetuating the same old strategy, just does not seem to fit.

The quotation at the head of this article has been included because few statements tell us more about Fisher's methods. The fact that a serving flag officer was in regular and informal correspondence with his nation's prime minister shows how thoroughly Fisher had mastered the Whitehall "system." It is also indicative of the lengths to which he would be prepared to go in order to gain the necessary political support for his reforms. ${ }^{8}$ Fisher was perhaps the prototypical "political Admiral." His stubbornness and his legendary reluctance to explain himself to anyone are obvious, as is the enthusiasm that he shows for his "modern cruiser." The fact that this letter was written at the very beginning of 1904 also demonstrates that, long before he was to introduce the Dreadnought, he was already of the opinion that the battleship type was likely to soon be eclipsed by this faster and hard-hitting derivative of the armoured cruiser. ${ }^{9}$ Finally, his mention that he might well be able to persuade Sir Andrew Noble of the Armstrong \& Whitworth shipbuilding conglomerate to act on his cruiser ideas as a private venture is doubly mischievous. Beyond the rather less-than-subtle "prod" for the government to accept the need for change, there is the suggestion he had career prospects outside the navy. More than once during Fisher's career, when he sensed that he was at the end of the road having stirred up too much opposition by his outspoken ways, ${ }^{10}$ he tended brazenly to threaten resignation, particularly if he wanted something done. Each of these personality traits is important in understanding the way this story plays out.

Fisher's intentions notwithstanding, it is an inescapable fact that Great Britain did plunge headlong into another round of battleship escalation while the more important parts of his "revolution," the submarine and battlecruiser, had much less impact. What

or "modern" cruiser.

8 While still indicative of immense persuasive drive, this may not be so unprecedented in Fisher's case. He had been a member of the Board of Admiralty on at least two occasions in the past (interspaced with operational commands), and latterly as the second sea lord, where he had gained an intimate knowledge of the workings of politics in Whitehall. It is therefore more understandable that he would have continued to cultivate and develop these connections, particularly in advance of his return as the senior sea lord.

9 In fact, in a letter to Arnold White dated 28 January 1901, he talks in the same fashion about a "battleship and cruiser built on revolutionary principles; oil fired, turbine driven, equal gunfire all round...that will stagger humanity!" See $F G D N, 1$ : 185. It seems therefore that the design of his new ship were fairly clear in his mind whilst he was in the Mediterranean as CinC.

10 The three most obvious times were in 1902, after his time in the Mediterranean, where he had been something of a thorn in the Admiralty's side with his demands for more cruisers and destroyers; in 1904, while in "limbo" prior to the confirmation of his appointment as first sea lord; and again, most brazenly in early 1905, when, as the new first sea lord, he had written to the King (via his private secretary) enclosing an offer of employment from Armstrong \& Whitworth, almost daring him to endorse his controversial reforms. One is left with the impression that either course would have suited Fisher. See his letters in FGDN, 1: 185, 222, 230, and 2: 53. 
went wrong? Fisher would seem to have been completely successful in his initial quest to have naval procurement swayed heavily in favour of his "modern" cruiser as early as 1905. Yet it was the single battleship ordered in that same year that gained the following, ${ }^{11}$ despite her creator's avowed intent to replace her and her kin with something better. There has not yet been a satisfactory explanation. The aim of this paper is to address this specific point, exploring the possibility that the answer lies somewhere in the wider pressures upon the first sea lord. While modern archival work has charted the main economic and technological drivers of change in the Royal Navy, it is this author's belief that a full understanding will only be possible by looking at the mercurial Fisher's whole spectrum of activities. The essential starting point in grasping Fisher's role is the complex field of institutional dynamics - looking at why the Navy, as a whole, responded in the way that it did to the particular circumstances of the period.

The preference for Dreadnought is often attributed to the threat posed by Germany. This view overlooks the fact that, as the world's premier sea power with many advantages over challengers, the Royal Navy was in a strong position to lead the way in naval strategic thought and thereby further strengthen British predominance. Sadly, however, through institutional inability to assess technological, economic and political developments appropriately, the Royal Navy as a whole remained wedded to an obsolete strategy. It was this fact, more than anything else, that allowed these "chimeras" from the past to be developed into a fully-fledged class of capital ships, something that arguably held back the development of naval strategic thinking for a further twenty years.

\section{Historiographical Background}

Any discussion of the Dreadnought phenomenon must begin with the work of Arthur J. Marder. Most subsequent analyses are either derived from or designed directly to challenge his work. For Marder, despite the fact that the 1905-6 naval estimates contained the provision for " 1 battleship and 4 Armoured Cruisers," it was all about the Dreadnought. ${ }^{12}$ A historian with a diplomatic background, Marder approached British naval policy from the standpoint that Britain's larger defence policy — grand strategy to use a later term - had already been established beyond any reasonable doubt before the building of Dreadnought. This assumption is the basis for the central theme of his landmark, five-volume treatise on the Fisher years (1961-70), which can be summarized as follows. ${ }^{13}$ Prior to the arrival of Fisher as first sea lord, the Royal Navy was in the doldrums. Overwhelmed by the pace of technological change and lacking any cohesive strategic direction as the Russian and French naval situations changed, British naval

11 The Navy Estimates for 1905-1906 stipulated the ordering of "four armoured cruisers" (one was later dropped) and only "one battleship." See The Times (London), 3 March, 1905, 12. This would seem to be in accordance with Fisher's plan.

12 Ibid., "The Navy Estimates 1905-1906, "Statement of the First Lord." For a more readable contemporary copy see Lord Brassey, The Naval Annual, 1905 (Portsmouth, 1905), 425-432.

13 Marder's classic work on the Fisher Era is his From the Dreadnought to Scapa Flow, 5 vols. (London, 1961-70). The majority of his observations on Fisher can be found in the first volume, The Road to War (1961). 
policy wavered. Fisher, with an eye towards an expansionist Germany, managed in short order comprehensively to reform the Navy and drag it into the Industrial Age in time to meet the challenge. The main vehicle that he used in his modernization program was the introduction of the Dreadnought battleship, a design that embodied his twin ideals of speed and hitting power, and one that he felt Britain's superior shipbuilding resources could produce more quickly and cheaply than anyone else. The key point to appreciate when considering Marder's work is that he believes that Germany had already been identified as the main threat to be countered. Thus the containment of her emerging battlefleet was what dictated the development of British naval policy and gave Fisher's reforms, including the Dreadnought, their true meaning. Although many have subsequently criticized Marder's methods, there is no doubt that at the time he wrote Marder had far and away the most commanding grasp of primary source material of any scholar. ${ }^{14}$

One measure of Marder's mastery of the archives, and his forthrightness as a scholar, is the fact that he published source material that supports interpretations quite different from his own. Fisher, in both private and official correspondence unearthed by Marder, seemed to indicate that the modern battleship's primacy as the sole arbiter of naval power was becoming questionable on a number of counts. Fisher, for example cited the increasing range of the "Whitehead" torpedo to underscore the fact that the operation of heavy ships off an enemy coast in waters infested with torpedo craft and submarines was becoming unacceptably risky. ${ }^{15}$ When the only way to threaten a battleship had been with vessels of the same class then battleship primacy made sense but to Fisher's way of thinking, those days were long past. The advent of fast torpedo craft and the long range torpedo had effectively put battleships within the killing reach of even small navies on a limited budget. The increasing - skyrocketing - costs of modern battleships, moreover, meant that the navy could procure fewer vessels. Deployment of new weapons technology on only a limited number of platforms would reduce the effectiveness of those weapons. ${ }^{16}$ Fisher therefore believed the time was ripe for what we

14 See in particular Jon T. Sumida, "Demythologizing the Fisher Era: The Role of Change in Historical Method" Militargeschichtliche Zeitschrift LIX, no.1 (2000): 171-181. Sumida categorizes Marder as a "scissors and paste" historian whose "approach began and ended with the sources. His inquiries were not prompted by independent questions," in this case the true motives for Fisher's reforms.

15 In the same letter to Arthur Balfour that contains the quotation at the head of this paper is a short piece on submarines "In the course of a few years (it was then 1904) no Fleet will be able to remain in the Mediterranean or the English Channel! But at the same time submarines at Malta, Gibraltar, Port Said, Alexandria, Suez and Lemnos will make us more powerful than ever." See $F G D N, 1: 294$. Other letters with similar sentiments appear on pages 253, 305-310. This is a clear reference to using submarines in the sea-denial posture of flotilla defence.

16 The practice of mounting torpedo tubes in battleships was a case in point - and was already becoming suspect at this time. A good discussion on the relative costs of large battleships as compared to medium sized ones can be found in Brassey's Naval Annual, 1905, ch.1 "The British Navy", 2-3. Brassey makes the point that three of the latter can be built for the same 
would call today a "capabilities-based" appraisal: an assessment of the fundamental necessities of the sea fight and a hard look at how these might best be provided, if necessary by the adoption of a completely different set of platforms. For Fisher, the two essentials in any sea fight were speed and hitting power. ${ }^{17}$

More recent scholarship has picked up on these important elements in Fisher's thinking, asking the questions that Marder did not address. Jon Sumida, for example, was one of the first to develop the financial side of the argument. In his important analysis of the impact of finance and technology on British naval policy (1989), he makes the case that it was the impending fiscal crisis that Great Britain faced in the early years of the last century and the consequent limits that were imposed on naval spending that gave life to the need for a radical re-think as to how the naval mission should be resourced. ${ }^{18}$ It was impossible to continue the construction of up-to-date warships in the numbers and varieties required to protect all of Britain's maritime interests and the choices were therefore simple. Either the Royal Navy would have to drop some commitments by prioritizing its efforts, or else it would have to look for imaginative ways of doing more with less. This challenge was perhaps most ably summarized by Lord Selborne, the first lord of the Admiralty when Fisher became first sea lord: "They (Sea Lords) must cease to say 'This is the ideal plan; How can we get enough money to carry it out?' They must say instead 'Here is a sovereign; How much can we squeeze out of it that will really count for victory in a naval war?" ${ }^{19}$ For an ardent patriot like Fisher, there was only the one pathway - to develop new and imaginative ways of meeting the full strategic needs of the nation and preserving British naval primacy, even if this meant questioning the battleship as the yardstick of sea power.

Charles Fairbanks, Jr., writing in 1991, underscores the fact that Marder hardly discusses the battlecruiser. ${ }^{20}$ With a different emphasis than Sumida, he also challenges

price as two large battleships - and while the larger ships are faster and better protected, the three smaller ones will always have the advantage in firepower. As he puts it "the policy of putting so many eggs in the one basket demands serious reconsideration." This was a hot topic for discussion in the naval press at the time.

17 Perhaps the best contemporary explanation of Fisher's thinking on speed and gun power in large ships is found in a lecture from Julian Corbett to the Royal United Services Institution published in July 1907, RUSI Journal LI, pt. 2 (July-December 1907): 824-833. This was instigated by Fisher himself, in response to criticisms being received from Admiral Custance (lately director of naval intelligence) who was writing in the Blackwood's Magazine under the pen-name "Barfleur." Fisher congratulates Corbett accordingly — see FGDN, 2: 120. For a more general, contemporary discussion on the pros and cons of high speed in capital ships, see Brassey's Naval Annual for 1906 (Portsmouth: 1906), 144-155.

18 Jon T. Sumida. In Defense of Naval Supremacy: Finance, Technology, and British Naval Policy, 1889-1914 (Boston MA, 1989) (hereinafter referred to as IDNS). See in particular chapter 1, 3-35.

19 Quoted in IDNS, 26. Lord Selborne was first lord of the Admiralty when Fisher was appointed to Whitehall in October 1904, and the two had developed a good rapport.

20 Charles H. Fairbanks, "The Origins of the Dreadnought Revolution: A Historiographical Essay," The International History Review XIII, no.2 (May 1991): 246-272. See in particular p. 247. 




Illustration 2: Sir John Fisher, in the uniform of First Sea Lord, circa 1916 Source: Press Portrait Review. 
Marder's "inevitability" thesis, which suggests that Dreadnought was built simply because other powers, most notably Germany, were making similar plans. While there is evidence to counter Fairbanks' outright dismissal of foreign competition, he is nonetheless right to take issue with this characterization of strategic thinking in the Admiralty. ${ }^{21}$ If this were the sole reason for the construction of Dreadnought, it suggests that Britain was purely reactive, which would have been a surprising stance for the world's premier sea power. Fairbanks, building on Sumida's battlecruiser thesis, argues that the prime mover for both the Dreadnought and the Invincible types was the need to rationalize ammunition and gun types in the interests of economy and gunnery efficiency. Only in this way could an affordable answer be provided to the French "Jeune Ecole" challenge of ocean commerce raiders. ${ }^{22}$ He therefore rightly broadens the description of Fisher's strategic thinking from a preoccupation with Germany into the wider realm of global commerce protection.

21 In the popular naval annual Jane's Fighting Ships for 1903 (and again in 1906 and 1908), Vittorio Cuniberti, the celebrated Italian ship designer, had sketched out the plans for what he called "an Ideal battleship for the British Fleet." The significant feature of this vessel was that its main battery was made up of a single calibre of gun $(12 \times 12$-inch). Cuniberti argues that such a vessel would not be worthy unless it were furnished with the means to overtake any enemy vessel and oblige them to fight (references to speed and hitting power). It is inconceivable that a naval and gunnery enthusiast like Fisher would not have been aware of this article. In the same year Lieutenant Homer Poundstone USN, came out in favour of a battleship proposal for a uniform armament of twelve 11 inch guns in the influential U.S Naval Institute Proceedings XXIX, (1903): 377-411. Again, it is inconceivable that Fisher would not have been aware of this evidence of American interest in uniform armament.

22 The words Jeune Ecole mean quite literally the "young school." This was a group of reformminded, mid-grade officers in France under the leadership and tutelage of Admiral Théophile Aube. Angry at the complacency and inactivity in the naval leadership and anxious to implement reforms, this group looked to restore France's maritime pride by challenging Great Britain. Their methodology was to target areas where Britain was weak, and they specifically focused on torpedo attacks to weaken the Royal Navy's battle line and also to carry out commerce raiding on Britain's huge merchant fleet. In strategic terms, the concentration on the secondary effects of a collapse in the shipping insurance market was masterful. With Great Britain carrying considerably more than 50 percent of the whole world's sea trade, it stood to reason that her economic interests would suffer disproportionately high penalties from any loss of confidence in the ocean trading market. Starting with the 6,500-ton, 20 knot Dupuy de Lome of 1890, France produced a whole series of large and fast "armoured cruisers" that were openly aimed at attacking British trade on the ocean routes. The key was their speed, which had to be faster than the average battleship, their long endurance and their protection, which needed to be a complete shell of Harvey or Krupp steel armour. This, theoretically, would make them very durable in oceanic raiding operations and, with their powerful armament of quick firing guns, they were designed to be a worthy match for the types of obsolescent battleships that Britain stationed overseas and just might catch them unawares and unable to flee. The problem was that these ships became, out of necessity, very large and therefore were immensely expensive to produce and often required a larger complement of men than an equivalent battleship, particularly in the engine and boiler room departments. 
Fairbanks explores the relationship between Fisher's proposed battlecruiser and the armoured cruiser. He explains that the real selling point of the armoured cruiser, apart from its speed, was the fact that it used medium-calibre (below 10 inch) quick-firing ordnance that was considered more accurate than heavier guns and had almost the same penetrating power on account of its higher muzzle velocities. In fact, he makes the case that Fisher had been an early advocate of the medium-calibre gun even for battleships, a point that will be developed later in the present discussion. ${ }^{23}$ Unfortunately, the size, complexity and cost of armoured cruisers grew at an unprecedented rate to the point where he had to contemplate "fusion" designs in order to bring expenditure under control. He sought to "merge" the best qualities of cruisers and battleships into one, general purpose, speedy ship. ${ }^{24}$ To note is Fairbanks' argument that it was the superior fighting utility of the all quick-firing batteries of the armoured cruiser, and not just its superior speed, which had initially attracted Fisher to the type. It therefore follows that economy through rationalization of gun types was important to Fisher, and hence a feature that he would seek in new classes.

Nicholas Lambert, in a series of articles and a book (1999), has broadened the discussion of technology, notably to include the development of submarines. ${ }^{25}$ In doing so he convincingly explores the strategic problems facing Fisher. Lambert concludes that Britain had three main imperatives - to defend the homeland, the empire and finally the vast network of interconnected global trade routes. By the turn of the century, Fisher realized that the conventional approach to these needs, that of employing three specialist platforms - the battleship, the station cruiser and the armoured cruiser - was no longer affordable or even tactically sound. The battlefleet, as we have seen, was now vulnerable to the torpedo in the shallow waters around the homeland, while the speed and range of modern heavy warships meant that the less capable station cruisers scattered around the world on basically diplomatic duties were vulnerable. Fast squadrons of armoured cruisers could pose a real threat to these vessels which were neither strong enough to fight, nor fast enough to run away. ${ }^{26}$

Fisher's elegantly simple solution was to play to the strengths of the new technologies. If submarines and torpedoes were making the shallow seas unacceptably

23 See IDNS, 39-42.

24 See Fairbanks, "The Origins of the Dreadnought Revolution," 259-263.

25 Lambert first expounds his theories in a pair of articles written in 1995. The most important to our discussion is Nicholas A. Lambert, "Admiral Sir John Fisher and the Concept of Flotilla Defence," Journal of Military History LIX (October 1995): 639-660. For his full analysis see Sir John Fisher's Naval Revolution (Columbia SC, 1999), in particular chapter 3.

26 Fisher is extremely disparaging about the smaller, obsolescent cruiser types that were traditionally used in their twilight years to police the distant empire. Calling them the "snail" and "tortoise" classes, he points out the waste of resources that was incurred by maintaining them, the wastage of manpower in manning them (manpower that needed to be trained to fight), and the fact that, were they to be challenged by an armoured cruiser, an eventuality becoming very real with the "suddenness" of modern naval war, they would be eaten up like an armadillo eats up ants! See Naval Necessities (written 1903) in Fisher Papers, 30. 
risky for the battlefleet, then move the battlefleet out of harm's way and rely on these same systems in British waters to deter any potential invader. Similarly, Britain needed to develop "flying squadrons" of powerful armoured cruisers that could respond quickly to events around the world when needed and do away with station cruisers permanently based overseas. In effect, the submarines and these "super" cruisers would take the place of the three specialist platforms, with the promise of considerable savings. Submarines were much cheaper than major surface warships, as were flying squadrons based in Britain as compared to existing arrangements to maintain more numerous station squadrons at costly overseas bases.

Yet, as both Lambert and Sumida explain, these strategic concepts required more capable submarines and faster, more powerful cruisers than existed in 1904. If these latter vessels were to use their speed to advantage and still prevail in combat with armoured cruisers and older battleships, then they would have to be able to deliver a knock-out blow from long range - something that had been proving elusive to say the least. Fisher, however, believed that, here again, technology was fast coming up with the answer. He was of the opinion that a true-course calculator being developed by Arthur Pollen, the "Argo clock," was about to provide a revolutionary solution to the problem of long-range hitting. ${ }^{27}$ While there is no space here to dwell on the technical aspects of the system, it is important to appreciate that the whole idea of a lightly protected ship being able to strike with impunity beyond the effective range of its opponents depended upon the fire control problem being solved in short order. ${ }^{28}$ In essence, there could be no effective battlecruisers without first having an accurate, long range gun. Thus Pollen's invention, or an equivalent, was vital to Fisher's plan.

Before concluding this brief survey, mention has to be made of a recent and provocative piece from John Brooks, "Dreadnought: Blunder or Stroke of Genius?" (2007) ${ }^{29}$ Brooks' central point is that in departing from the Admiralty's long-standing policy of not promoting radical advancements, the Fisher team erred significantly with the Dreadnought. Instead of relying on Britain's superior shipbuilding capabilities to react decisively to any foreign innovation, Fisher's team needlessly risked promoting the

27 The crucial point to take away here was that Fisher would need to have been aware of these advances before he made his Dreadnought decisions in 1905. Looking back through his correspondence, it is clear that the Admiralty had been interested in the device since 1904 and were largely satisfied with the inventor's claims. John Jellicoe, a Fisher protégé and fellow gunnery officer, had been instrumental in promoting Pollen's equipment — and it is therefore inconceivable that Fisher had not been kept informed of progress. See Fisher's letter to the new First Lord, Lord Tweedmouth, recommending that the apparatus receive national patent protection, FGDN, 2: 87.

28 For a thorough description of the Pollen apparatus, see Jon T. Sumida, "British Capital Ship Design and Fire Control in the Dreadnought Era: Sir John Fisher, Arthur Hungerford Pollen, and the Battlecruiser," Journal of Modern History LI, no.2 (June 1979): 212-217. See also John Brooks, "All Big Guns: Fire Control and Capital Ship Design," War Studies Journal 1 (1996): 36-52.

29 John Brooks, "Dreadnought: Blunder or Stroke of Genius?" War in History XIV, no.2 (2007): 157-178. 
very rivalry they wanted to avoid by plunging ahead with a design that demanded a response, particularly from Germany. While not refuting the possibility that Dreadnought-style vessels were inevitable, he maintains that a further, evolutionary step with the pre-Dreadnoughts under the traditional Admiralty policy would not have impaired Britain's security, quite the reverse. It would have delayed further escalation of the naval building race, which was in Britain's interest.

It is for discussion, however, whether Brooks may have approached this question from the wrong starting point. In a work that hardly mentions the importance of the battlecruiser to Fisher's plans, Brooks proceeds from the basis that Dreadnought herself was the crucial advance and not, as Fairbanks has characterized, merely an unfortunate by-product of an "aborted Invincible Revolution." ${ }^{30}$ Brooks' work cannot help us decide whether the Dreadnought was a genuine "blunder" or a "stroke of genius," because it does not look at the full reasoning behind Fisher's initial intentions. Had he examined this story from the point where Fisher's rationale for the armoured cruiser began, he would have seen, for example that, with the Invincible type in prospect (and ordered), there was really no point in continuing with modified pre-dreadnought Lord Nelsons, whose limited heavy armament and more particularly slow speed would have been as fully evident as it was in comparison with Dreadnought. Equally, construction of improved Lord Nelsons would not have served to advance naval knowledge in the meantime. Thus, while parts of Fisher's methodology may be criticized, his realization that Dreadnought, as a turbine-driven, uniform-calibre ship was a logical interim step towards the Invincible was probably not one of them.

While there are many points of disagreement among these recent studies, collectively they represent a mature scholarship built on well developed research that can amply sustain alternative approaches. The present paper seeks to reorient the axis of the enquiry, so to speak, to consider the wider issues of timing, personalities, the media, public perceptions and their roles in these decisions. Specifically, there is a need to understand why the usually calculating Fisher, having seemingly gained everything he wanted in the 1905-6 estimates in terms of his new class of battlecruisers, decided to press on and give priority to completion of the single battleship (Dreadnought) ordered that year. This was clearly going to leave him in an awkward situation when it came to future procurement decisions.

\section{Three Reasons to build Dreadnought.}

One of the basic and long-standing tenets of British naval construction when Fisher became first sea lord was to order a minimum of "four large armoured ships a year" to maintain the "Two-Power standard" of 1889, still the basis of British naval policy. ${ }^{31}$ This meant that for the three annual naval estimates between the completion of

$30 \quad$ Fairbanks, "Origins," 259.

31 The "Two-Power standard," as it became known, was first introduced in Parliament during the Naval Defence Act debates in 1889. The first lord of the Admiralty, Lord George Hamilton is quoted thus: "I think I am correct in saying that the leading idea has been that our establishment should be on such a scale that it should at least be equal to the naval 
the Dreadnought's trials in November 1906 and the evaluation of Invincible as a weapons system in 1909, there was no real guidance as to which of these two classes was the more promising, and thus which should be ordered to fill the requirement for "four armoured ships" for each of these years. ${ }^{32}$ Fisher must have been acutely aware of this uncertainty and so one is left wondering why he seemingly did nothing to manage the inherent risk. In fact, his insistence on the Dreadnought's accelerated building schedule arguably made matters worse. The 1906-7 estimates were always going to be a particularly challenge because, not only were the Invincibles an unknown commodity at the time, but Dreadnought herself would not have been evaluated. The wording in these estimates was somewhat vague - simply referring to "four armoured ships, presumably of the Dreadnought variety." ${ }^{\prime 3}$ The only real concession to these difficulties was an agreement to defer "to a comparatively late period of the session - somewhere around June" the consideration of the shipbuilding vote, presumably so that specifications could be drawn up on the basis of experience from the Dreadnought trials. ${ }^{34}$ While this postponement made eminent sense, why then did Fisher, if he truly believed that the future belonged to a different force composition, choose to introduce the technological advances that were central to this change with the very same platform that he was hoping to replace?

Three alternative hypotheses spring to mind. First, and accepting that there was an urgent need to demonstrate that turbine propulsion could successfully be used in large warships, he may have felt that a turbine driven battleship would convince the doubters more thoroughly than the introduction of the new machinery in a lighter and faster, cruiser-style hull. In other words, a battleship "technology demonstrator" would carry more weight, especially for those who only tended to measure naval power in terms of the battle line. Second, he may have recognized that, even if he had been successful beyond his expectations and the battlecruiser concept had gone forward, it was still most unlikely that the British public could be convinced within the space of a few months that the age of the battleship was over. ${ }^{35}$ This would mean that, come what may, battleships would almost certainly be built for at least the early years of the transition. In which case, it made sense to ensure that these ships were as close to his ideals for this type of

strength of any two other countries....Supremacy at sea must, after all, be measured by the number of Battleships we can put into the line." See Parliamentary Debates, Vol. 333 (1889). The Cawdor Memorandum, which was presented to Parliament in November 1905 and published in December of the same year, updates this policy in terms of its implications for shipbuilding. The following extract is pertinent: "At the present time strategic requirements necessitate an output of four large armoured ships annually..." For the full speech, see Brassey's Naval Annual for 1906, 353-362.

32 These were the naval budgets to be announced in March of 1907, 1908 and 1909.

33 See Naval Estimates, 1906-7, released on 1 March 1906 and reproduced in The Times (London), 2 March 1906. Although listing "four armoured ships" the number was later dropped to three battleships - the Superb class of Dreadnoughts.

34 See a leader written by James Thursfield in The Times (London), 2 March 1906.

35 See for example his tacit admission that the "time might not yet be ripe for the abolition of battleships" in his instructions to the "Committee of Seven" in 1904, Fisher Papers, 41-42. 


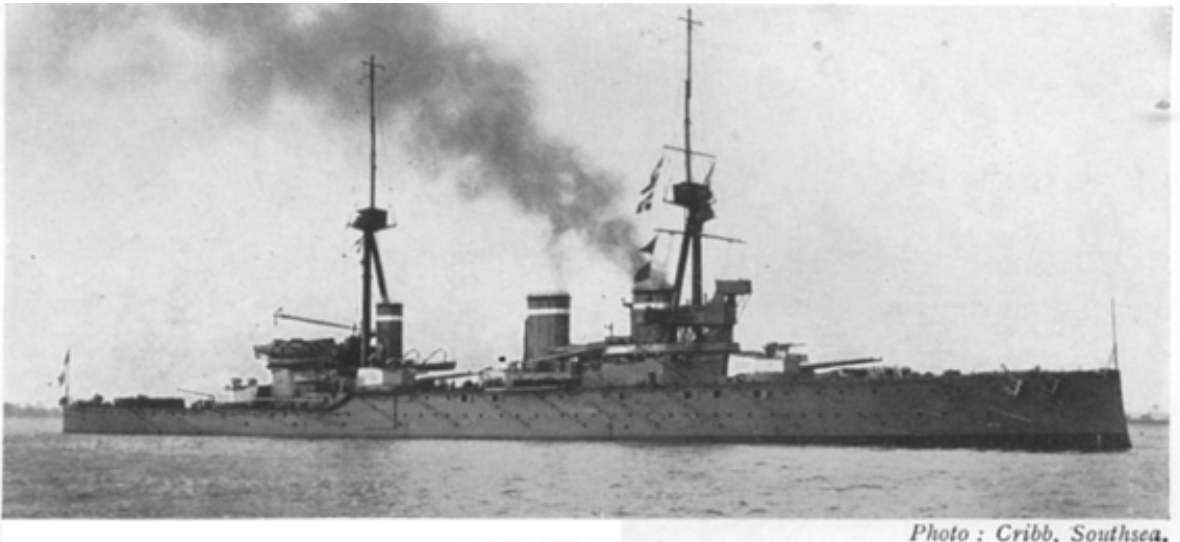

H.M.S. Invincible.

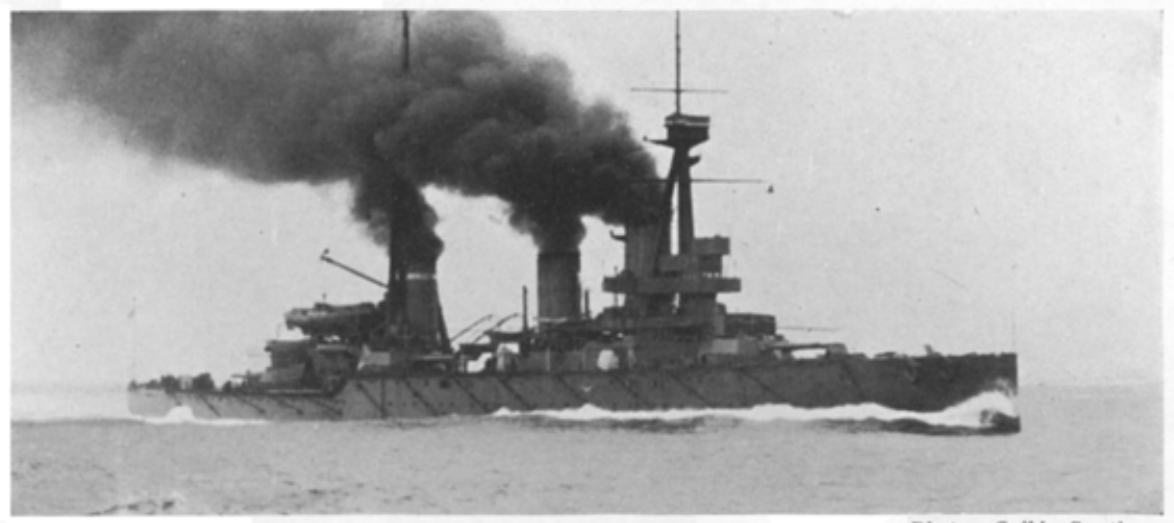

H.M.S. Indomitable.

Photo: Cribb, Southsea.

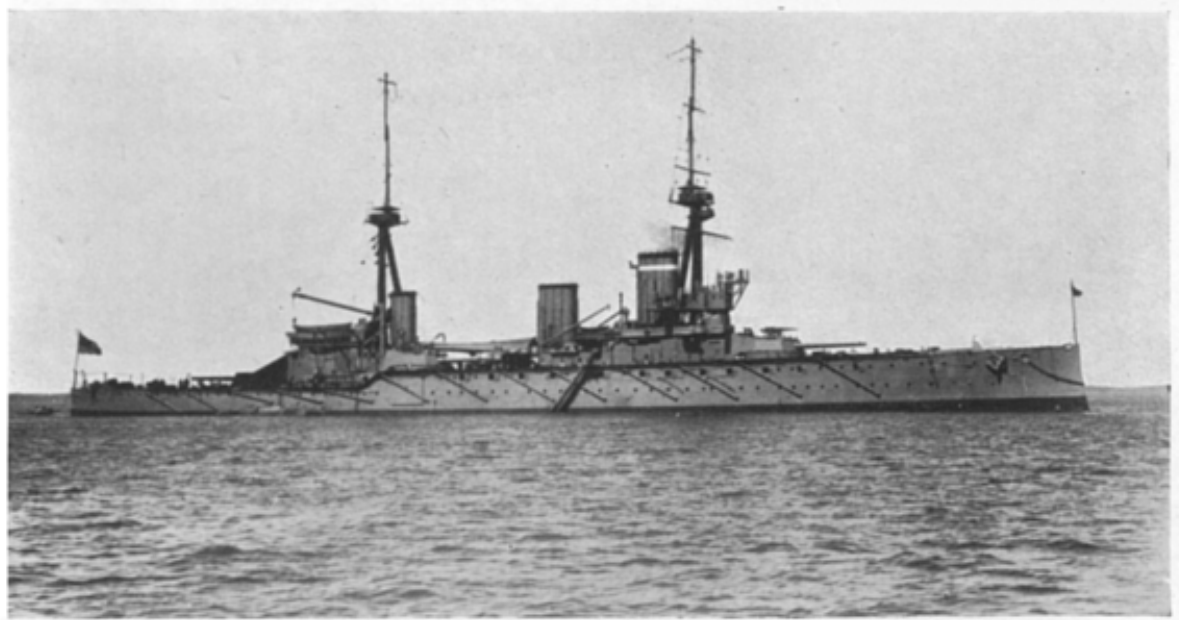

H.M.S. Inflexible.

Photo: Cribb, Southsea.

Illustration 3: The three ships of the Invincible class. Adapted from Filson Young, With the Battle Cruisers, London, 1921. 
platform as possible — being faster than the existing types and equipped with the powerful uniform calibre main armament. ${ }^{36}$

Finally, there was the more mundane issue of where the two designs were developed. Dreadnought was the brainchild of Sir Philip Watts, the director of naval construction (DNC), and was therefore an "in house" product, whereas Invincible had come from the draughtsmen of Armstrong-Whitworth, a private yard. It was inconceivable therefore that the latter design could be given at this late stage to a navalowned yard to construct, and yet there were great advantages to be had by building these ships in yards where the Admiralty, and Fisher specifically, could oversee and accelerate the building process where necessary. Speeding up production had always been one of Fisher's goals with his new ships, not only to promote more efficient practices, but also with a view to the deterrent effect that showcasing such ship-building prowess would have on others. ${ }^{37}$ Under these circumstances, Fisher may well have reasoned, quite rightly as it turned out, that he would have more control over the battleship build in Portsmouth, a yard he knew well, than he ever would at Armstrong-Whitworth. ${ }^{38}$ Being able to forge ahead with indecent haste and thereby stun his rivals into hesitation with their own building programs might have seemed a worthy compensation for losing a tight grip on his battlecruiser. It is quite possible that all three of these alternative explanations may have had some influence along the way, but, to gain further insight here, it is necessary to go back into the contemporary documentation.

\section{The "Uniform-calibre" Battleship}

"The Battleship of olden days was necessary because it was the one and only vessel that nothing could sink except another battleship. Now, every battleship is open to attack by fast torpedo craft and submarines...ALL THIS HAS BEEN ABSOLUTELY ALTERED!...The battlefleet is no protection to anything or any operation during dark hours and, in certain waters is no protection in daytime, because of the submarine. Hence what is the use of Battleships as we have hitherto known them? NONE! Their one and only function, that of ultimate security of defence - is gone - lost!" Sir John Fisher, May 1904. ${ }^{39}$

$36 \quad$ Ibid., 42.

37 For a good exposé of the rationale behind Britain's desire for speedy and efficient warship construction, see the "Shipbuilding Policy" piece in the "Cawdor Memorandum" of November 1905, published in full in Brassey's Naval Annual for 1906, 359-360. Fisher himself desired great changes in the Dockyards in order to speed up repairs and shipbuilding. See FGDN, 2: 46 and Fisher Papers, 23.

38 In fact, Invincible's construction was dogged with labour disputes, which delayed her completion by at least three months. See Tarrant, V.E. Battlecruiser Invincible (London, 1986), 17. This was exactly the fear that Fisher had concerning the lack of Admiralty control in the commercial sector.

39 Fisher Papers, 30-31. Fisher, after painting this gloomy prospect for the battleship of the old school (pre-dreadnought), rejoins with the fact that the only justification for his new battleship (Dreadnought) is that, with its speed and gun power, it is basically just an armoured cruiser. 
In a paper entitled "Naval Necessities" that he first circulated to his "committee of seven" whilst still at Portsmouth in May 1904, Fisher emphasizes that "the new Navy, excepting a few special local vessels, [ought] to be absolutely restricted to four types of vessels, being all that modern fighting necessitates." 40 These four were a 21 knot battleship; a 25 knot armoured cruiser; a 36 knot destroyer equipped with 4-inch guns and modern, ocean-capable submarines. Interestingly, and despite his sentiments quoted above, the battleship still featured in his scheme as originally configured - although it is clearly a Dreadnought-type, and he stresses the need for a uniform armament to save on costs. $^{41}$ After such a damning indictment in the same paper, one is left wondering why. While this could certainly be something of an endorsement for the "inevitability" hypothesis for continued battleship production, we may be running into the legendary Fisher inconsistencies. For example, later on in the same paper he seems to make the argument that, with the conventional (i.e. pre-Dreadnought) battleship effectively "dead" as a concept, the fast battleship (his Dreadnought) was the only realistic option for Britain and that essentially this was nothing more than a glorified armoured cruiser. ${ }^{42}$

This seeming confusion between the types was not unprecedented - in fact there is evidence that Fisher's thinking had long fluctuated between the need for true armoured cruisers, specialized for long range and speed, and the all-medium-calibre battleship. ${ }^{43}$ This latter type of vessel was one in which a speed advantage was generated by compromises in the main armament on the basis that it was the powerful, secondary battery of quick-firers that really counted. Basically, by employing more of the armoured cruiser-style, quick-firing guns in lieu of the slow firing heavy main armament of the battleship, weight was saved that could be translated directly into either more speed or better protection. ${ }^{44}$ The problem, after all, with the conventional battleship was that its

40 Ibid., 22. Interestingly, the "Committee of Seven" contained many future "Fishpond" supporters, being comprised of Captains Henderson, Jackson, Bacon (soon to be his flag captain), Jellicoe (later commander-in-chief of the Grand Fleet and a long time Fisher protégé) and Madden. These were joined from time to time by William Gard a naval architect from Portsmouth and Alexander Gracie of Cammell-Laird shipbuilders, whom Fisher termed "the best Marine Engineer in the world!"

41 Ibid., but with a more thorough rationale in a secret annex to the original notes, reproduced on pages 32-34.

42 Ibid., 30-31.

43 See, for example his recounting of his experiences with his flagship Renown in manoeuvres her speed enabling him to "mop up" all the enemy cruisers, in two expansive letters on the benefits of speed in large warships to Lord Selborne when he was first lord of the Admiralty, in FGDN, 1: 170-179. HMS Renown was officially classed as a second class battleship, having only 10-inch guns for its main battery, as opposed to the usual 13.5 -inch, and a large battery of 6-inch quick-firing guns. The weight saving gave her a handy two knot speed advantage over her larger brethren however. She was built, on Fisher's own recommendation, when he was serving as controller in 1892. The Admiralty at large were not convinced however. See also IDNS, 40.

44 This was more than just a theoretical concept at this stage. Other navies, and in particular the Germans, were actively developing all medium-calibre battleships to take advantage of the 
very slow rate of fire made it vital that every shot count - something that was simply not possible with the fire control systems of the time. In contrast, the strengths of the medium-calibre battleship and armoured cruiser were tied to the "shredding effects" possible with their preponderance of quick-firing guns. These guns had a vastly superior rate of fire which allowed rapid correction of range and training, greatly increasing the likelihood of effective hits. ${ }^{45}$ Further, because medium-calibre quick-fire guns were much lighter than heavy guns, many more could be mounted in the same size of hull, increasing the likelihood that medium-calibre ships could deliver a devastating hail of fire at near the maximum effective range of naval engagements with the real potential to disable or demoralize an opponent in short order. Best of all though, this could likely be achieved without any real advances in gunnery techniques being necessary.

A turbine powered medium-calibre battleship could also be expected to enjoy a small advantage in speed and handiness when compared to a conventional preDreadnought, another critically important asset when combined with the hitting power of the uniform quick-fire armament. Even with only a slim margin of speed, these vessels could gain the initiative in an engagement, choosing when and how long to close to fighting range, and thus the power to overcome other battleships of supposedly superior capabilities. The fact that these platforms would be less expensive and difficult to build than conventional battleships, moreover, meant that they could be acquired in sufficient numbers to undertake some Imperial duties as well. Such a ship could potentially enjoy most of the advantages of the armoured cruiser without succumbing to the need for excessive specialization. It would certainly be quite sufficient to overcome all but the fastest armoured cruisers afloat. Thus, although fundamentally different, both the armoured cruiser and the medium-calibre battleship offered similar strategic advantages. The key to this new battleship's practicality would be the turbine power that would deliver extra speed at a moderate cost compared to conventional battleships. In any event, such a vessel, whilst not the high-speed, quick response defender of overseas trade and Imperial territories of Fisher's dreams, would seem to offer a plausible interim solution, especially if it were paired with faster and similarly armed armoured cruisers.

It is not beyond the bounds of possibility that these same considerations might later have come to bear once the realization of a quick-firing and accurate heavy gun became likely. How would this eventuality have altered the equation? It would have been a logical extrapolation of Fisher's ideas to develop a vessel that merged the versatility of this fast platform for uniform calibre armament with the greatly increased hitting power of the improved heavy guns. ${ }^{46}$ All he would need was assurance that no

accuracy and rate of fire advantages of quick-firing ordnance. For a good description of the rationale behind the 1899 build of SMS Kaiser Karl der Grosse, see Theodore Ropp's classic study on the French Navy in this period, The Development of a Modern Navy: French Naval Policy, 1871-1904 (Annapolis MD, 1987), 297-299.

45 For a discussion on this, see IDNS, 40-50.

46 For a good contemporary discussion of the merits and otherwise of the 6-inch battery $v s$ the 12-inch battery in ship killing terms, see an article entitled "Do Dreadnoughts only count?" by "Navalis" in the Fortnightly Review (June, 1909): 1096-1099. While acknowledging the impressive rate of fire of the quick-firers, the author concludes that "there can be no 
insuperable difficulties would unduly delay solutions of the accuracy and rate of fire problems with the heavy gun, an assurance that seems to have been provided by his design committee. ${ }^{47}$ Such a combination, a uniform heavy-calibre quick firing armament with speed - a Dreadnought in all but name - would obviously have clear advantages over a ship with a uniform medium calibre armament, even if it were no closer to Fisher's ideal armoured cruiser. Still, if the armoured cruisers were to be procured as well as the battleships with a uniform heavy quick-firing armament, then the advantages to the Royal Navy would be commanding. This would seem to support the proposition that, if battleships were to be a fixture at least for the short term until the battlecruiser concept was proved, then it made sense that Fisher would seek to make these battleships as formidable as possible.

\section{Other Considerations}

Another factor in support of the immediate priority for Dreadnought was undoubtedly the widespread reluctance within the navy, the government and the public to accept that the battleship was really about to be superseded. ${ }^{48}$ Fisher, in encountering resistance to his super cruiser theories, may have become resigned to the fact that the time was not yet ripe for the complete supersession of the battleship by the battlecruiser - in which case the next best answer would be to make a faster, uniform-calibre battleship, whose evident advantages in speed and a uniform calibre armament would help build the case for the battlecruiser. In other words, he probably came around to accepting the need for a two-stage process - battleship to fast battleship and finally to battlecruiser. ${ }^{49}$ This could also explain why he pushed the Dreadnought through with such haste: to get past the interim steps as soon as possible so that he could carry on and build some real ships!

This idea is also supported by a study of Fisher's various design committees. Realizing that his chances of jumping straight to the battlecruiser were doomed politically, there is evidence that he next tried deliberately to blur the differences between

comparison between the destructive force of these and that of a large shell discharged from the 12" guns." Thus, and with the prospect of better fire control in the Dreadnought-type, he concludes that the all-big gun decision for the Dreadnought was the right one.

47 See a paper entitled "The One Calibre Big Gun Armament for Ships," Churchill College, Cambridge, Fisher Papers, FP 4881, FISR 8/31, page 10. The "Design Committee" of 1905 seemingly gave him that reassurance.

48 See for example Lord Selborne's marginal minute back to Fisher on Naval Necessities, adjacent to the part where Fisher states that the old-style battleship is basically useless. Selborne, referencing the Japanese successes in the then-current Far-East war, makes the comment that the Japanese certainly did not seem to agree that the battleship was dead! See Fisher Papers, 41.

49 There is evidence in his correspondence that, although he always believed that he could make the leap to the battlecruiser without an interim stage, he was finally in a minority of one (i.e. outvoted) in his committee. It seems that this was the point, in 1904, that he reluctantly accepted the need for Dreadnought in his plan. See a letter to Arnold White written a few years later in 1908, FGDN, 2: 188-189. 
this type and the fast, uniform-calibre battleship by organizing a committee to, amongst other things, study "the fusion of the battleship and the armoured cruiser." Endorsement would then have given him carte blanche to decide exactly what features to promote in these "fusion" types. In other words, he could potentially have achieved his goal by subterfuge - something that certainly would not have been outside his character. In the end, however, he was thwarted once again. This committee, meeting in the aftermath of the Russo-Japanese War, concluded that the strategic circumstances had altered sufficiently that the rationale for "super" armoured cruisers, or indeed any more armoured cruisers at all, was questionable now that Russia, the principal competitor in the most distant seas of British interest, had been decisively defeated. In addition the "fusion" type as tabled would likely have been very expensive as compared to Dreadnought, with no real gains in firepower. What advantages therefore were there in going down that route, when the only possible threat remaining in the near term came from Germany - a power that was building battleships and for whom Dreadnought was already a sufficient match?

In retrospect, forming this particular committee was perhaps the most crucial miscalculation that Fisher made. The resulting recommendations were that the "armoured ships" to be ordered in the 1906-7 estimates should be all "battleships of the Dreadnought type." 51 Fisher was in no position to overturn the recommendations of his own committee, particularly given the continuing and growing controversy over his methods in forcing through his broader reforms ${ }^{52}$ Had he done so, this would have given instant credence to his critics' complaints that the office of the first sea lord, as Fisher ran it, was becoming too authoritarian for the good of the Navy. A man as politically astute as Fisher was would likely have elected for discretion, at least for the time being.

A counterargument that needs to be explored concerns the wording of the 1905-6 Estimates. These would seem to have given him everything that he wanted. After all, he was authorized at a stroke to build both types, with the emphasis seemingly on the battlecruiser, and so, why didn't he forge ahead with the one, truly revolutionary ship? What better way to convince the doubters? This is a difficult question to answer but the third hypothesis proposed earlier may have been influential here; Dreadnought was the

50 See Sumida, IDNS, 59-60. Sumida lists the committee members as Captains Ottley (DNI), Jellicoe (director of naval ordnance), Bacon (Fisher's naval assistant), Madden, Nicholson, Jones and Commanders Orpen and Crease. It is significant that these were hand-picked "Fisherites" and at least three of them had been in his previous "Committee of five" and "Committee on Ship designs." There is little doubt that Fisher was "loading the dice," so to speak.

51 Navy Estimates Committee 1906-7 (10 January 1906), Churchill College, Cambridge, Fisher Papers, FP-4711, FISR 8/6, 20-21.

52 See in particular the anonymous article "A Retrograde Admiralty," Blackwood's Edinburgh Magazine CLXXVII (May 1905): 597-607. This was widely attributed to Rear Admiral Sir Reginald Custance, lately the director of naval intelligence, who was extremely critical of Fisher's methods. Custance criticizes Fisher for deliberately undermining the authority of the other Admiralty Board members, and in particular the controller, thus effectively turning it into a dictatorship. There is evidence that the article particularly incensed Fisher. 
design of Sir Philip Watts, the "in-house" director of naval construction, whereas the design of Invincible had been produced with Armstrong-Whitworth, a commercial yard. Watts would have certainly have insisted that his battleship design be produced in a naval dockyard - and what better option than to award this contract to the Portsmouth yard, with which Fisher was intimately familiar, having been closely associated with it at two previous points in his career. ${ }^{53}$ It was a venue where Fisher would have the freedom to wield his influence for to achieve the fast building time that he wanted.

While it is admittedly still conceivable that Armstrong-Whitworth might have been sympathetic to Fisher's needs, it is also true that any accelerated building schedule, with all the attendant reallocations of resources and labour that it would entail, would be far more likely to attract unfavourable shareholder scrutiny given the other commercial interests at stake. It may be that Fisher simply lacked the necessary leverage to accelerate Invincible, or to take the design to the naval yards, having already gone too far with Armstrong's to extricate himself with dignity. He may therefore have made the logical deduction that, since he was not going to get the necessary building influence at Armstrong-Whitworth, then an interim fast battleship built at Portsmouth was the quickest way possible to get to his battlecruiser. That being the case, the best thing that he could do at that point was to accept the two stage process and apply all his energies toward hurrying through the initial stage with Watts and Portsmouth Dockyard.

In sum therefore, it would appear that the most likely explanation is that Fisher, through a considered assessment of all these circumstances, made a pragmatic decision. It seems he concluded that the urgency of what he sought to do ought to be the deciding factor in how he would proceed. Speed above all things! Given the uncertainty about how his radical strategy was likely to be received, the need in his eyes for secrecy, and the likelihood that the battlecruiser was going to be some time in gestation, he pressed ahead with an interim solution in the shape of Dreadnought rather than waiting for something that might be years in the making. He would have the turbine at sea in a major warship and would be able to demonstrate the efficacy of the uniform calibre gun arrangement, not to mention the possibility of more progress with the Pollen fire control system. These achievements would likely help the battlecruiser to a faster acceptance when she eventually emerged.

The alternatives were really not that compelling. Could he have forced the time issue by offering the Invincible contract to an Admiralty yard? The answer is possibly, but this would have entailed a probable rift with Armstrongs, something that, for both professional and personal reasons, Fisher would have been unlikely to countenance. ${ }^{54}$

53 Fisher had been admiral superintendant of the dockyard in 1891 and had personally supervised the construction of the revolutionary battleship HMS Royal Sovereign, lead ship of the fleet expansion resulting from the Naval Defence Act and the yardstick against which pre-dreadnought battleships became judged. He had also held the position of commander-inchief, immediately prior to his return to Whitehall as first sea lord. Portsmouth, and its environs were well-known to Fisher.

54 This goes back to the point that, on at least two occasions in the very recent past, Fisher had been on the verge of signing on with Armstrongs as a sort of warship design "project 
Could he have stopped battleship production altogether while the battlecruiser build played out? Again, this was theoretically possible, as the Royal Navy has subsequently been shown to have been sufficiently far ahead of its rivals at that point, but this does not take into account the perceptions of the moment. ${ }^{55}$ In some respects Fisher seemed to favour a delay in battleship construction, but he was wise enough to realize that his was a minority viewpoint, and that his political sponsors were likely to take a contrary view. ${ }^{56}$ Why risk losing their support at a critical juncture? Besides, there was the not inconsiderable disadvantage that a temporary halt in large warship production would have on the naval shipbuilding capacity of the nation. Britain's naval strategy relied on the fact that its shipbuilders could produce battleships more quickly and cheaply than anyone else. These capabilities however depended on regular and predictable orders so that the necessary plant and infrastructure could be maintained. Thus, if Dreadnought had not been built, then the Admiralty would have been under considerable pressure to order something, and the only other choice would have been to build more Lord Nelsons - a type altogether inferior to Dreadnought in every respect, save possibly cost. ${ }^{57}$ Under these circumstances, moving ahead with Dreadnought seems a much more understandable choice.

manager." See $F G D N, 2: 53$. With his evident proclivity for upsetting authority, Fisher may have hoped to keep this door open at least, should another such episode force his resignation in the future.

55 There had been widespread outrage from all quarters over the Admiralty decision to drop just one battleship from the 1906-7 program, a decision taken based on the improving strategic situation for Britain in the wake of improved relations with France and the demise of the Russian threat after the Russo-Japanese War. See in particular the debates in the House of Commons for 27 July 1906 and the House of Lords for 30 July 1906, reported in The Times (London) of 28 and 31 July 1906 respectively. The focus of attention seemed to be on the issue of insufficient trust with respect to the recommendations of the Board. Given this concern over just one hull, Fisher may well have been forced to accept that he was never going to be able to argue for a complete pause in battleship production, no matter how much sense it made to him personally.

56 Pertinent here were the opinions of Lord Selborne, who although he had been superseded as the First Lord in 1904, was one of the few politicians for whom Fisher had genuine admiration. Selborne had opposed his thoughts on dropping battleship construction, see note 48 above.

57 In his Naval Annual for 1905, Lord Brassey estimates that a Lord Nelson class cost $£ 1,500,000$ in round figures, see page 2 . The Lord Nelson was the ultimate expression of the pre-Dreadnought type, being armed with a main battery of $4 \times 12$ inch and a large, mixed battery of quick firing guns of various calibre. The cost of Dreadnought is not so easy to gauge because of the "excessive secrecy" and the fact that the Admiralty employed a degree of "smoke and mirrors" in the accounting, because of Fisher's insistence on great speed in construction. In an article entitled "Admiralty Policy and the New Naval Estimates," William $\mathrm{H}$. White, himself a previous director of naval construction and the designer of the Royal Sovereign class in 1889 , makes the point that, in order to achieve these build-times, many of the complex sub-assemblies would have had to have been ordered in prior years' estimates, thus the quoted Admiralty costs of $£ 1,680,000$ were likely to be a gross under-estimate. See The Nineteenth Century LIX (April 1906): 601-618. 
Sadly for Fisher, the ramifications of the push for Dreadnought may well, in retrospect, have derailed the whole program. This was a situation made worse by the unusual secrecy that he insisted upon for both Dreadnought and the battlecruisers. ${ }^{58}$ By forcing Dreadnought through in just over a year, he saddled himself with a standard that was clearly unsustainable in the longer term. ${ }^{59}$ The norm was two years to build a large warship and the British production machinery was geared accordingly. Since the Invincibles were running on the original schedule and were laid down later, it was inevitable that the Dreadnought would be completed at least a year, possibly longer, before them - with all the difficulties that that was to entail for follow-on construction decisions. Indomitable, the first of the battlecruiser class to complete, was available for trials and evaluation only in the autumn of 1908, a full two years behind the Dreadnought, while her sisters (from the 1905-6 estimates) were completed in October of 1908 and March of 1909 respectively. This was to give the first sea lord something of a credibility problem in terms of his warship orders for the intervening years. After he promoted Dreadnought so energetically as a harbinger of the future, then why would he not order more of that type, especially as his battlecruisers were years away and still unproven? The very speed with which he had pressed construction of Dreadnought was going to wreak havoc with his quest to replace the battleship with his battlecruisers as Britain's standard capital ship.

58 In the same article, White, maintains that the "excessive secrecy" surrounding the Dreadnought and Invincible types was without precedent and was counterproductive. Since it has been impossible to hide such a large ship from professional eyes, the rival navies had the information they needed in any case and, in the meantime, the lack of official descriptions led to inaccurate speculations and a lack of public knowledge - which could easily be translated into either a lack of trust in the Admiralty or worse still, would lead to a lack of interest by the public in naval matters in the longer term. Neither was in the Navy's interest. White was not a fan of Fisher and was labelled by the latter as a part of the "syndicate of discontent." See The Nineteenth Century LIX (April 1906): 601-618. Even James Thursfield, the naval correspondent to The Times, who was very pro-Fisher, remarked in an editorial that "we have never been greatly enamoured of this policy of secrecy. It obtains little sanction from precedent or from established constitutional usage... it would seem to be highly expedient that the merits of the design, and otherwise be submitted to exhaustive public discussion before any further expenditure is sanctioned." See The Times, (London), 20 April 1906, 7.

59 In the same Nineteenth Century article there is a good description of the chaos that the acceleration of Dreadnought's building time caused the naval establishment. White maintains that the only way Dreadnought could have met the schedules imposed was through gross abuses of the system such as using sub-assemblies already paid for other vessels under previous estimates, and thus her progress was sure to have untold disruptive effects elsewhere. There was also the issue of dishonesty over her real costs and the fact that there was no possibility that such a schedule could be repeated in the future. To pretend otherwise was folly. The whole thing was therefore something of a damaging publicity stunt all round. See The Nineteenth Century LIX (April 1906): 614-616. 


\section{Conclusions}

This paper has explored some of the wider issues concerning the relative timings of the construction Dreadnought and Invincible. Why did Fisher decide to build any new battleships in 1905 when his intention was to replace the battleship with the battlecruiser type? Why moreover did he so energetically promote Dreadnought in 1906-7? While acknowledging that there is still a great deal of research to be done here, the present paper has endeavoured to show the central importance of these questions in understanding why Fisher's campaign to supersede the battleship type resulted in the battleship building race with Germany.

Fisher faced three big challenges in his bid to supersede the battleship. First, he needed to demonstrate that turbine propulsion and a uniform-calibre main armament were the right directions for capital ships to take in the future. Second, he needed a fallback plan for the eventuality that the political and naval establishments rejected his battlecruiser ideas, a plan that achieved, if at all possible, most of the expected benefits of this still speculative type. Finally, he needed to be able to have considerable personal influence over the running of these construction projects because it was obvious to him that quick progress was essential to realize his goals. The essential context was the declining financial situation and the consequent need for savings. This made it crucial that any new ideas could be defended and promoted in terms of the economies that could be realized. These considerations meant, for example, that the savings expected by adopting uniform types of guns and ammunition for capital ships were probably at least as influential in the selection process as the guns' performances.

It is proposed here that Fisher, realizing early on that the British political and naval establishments were unlikely to accede entirely to his proposals that the battleship be dropped as the prime component of the surface fleet in favour of the battlecruiser, came up with a plan that preserved the type, alongside the battlecruiser, but as a hybrid platform. This vessel, while slower than the proposed battlecruiser, was still considerably faster than the conventional battleship of the day. It also demonstrated the soundness of uniform-calibre armament. This sort of thinking would therefore explain why he chose to list the "21kt battleship" as one of the four ship types proposed in his Naval Necessities, despite his simultaneous protestations as to the battleship's diminishing utility in a modern sea fight. Obviously it was consistent with Fisher's character to make all his designs as powerful as possible but, and notwithstanding the promise of the new 12 inch guns and the improving gunnery techniques, it was probably the uniform-calibre argument that carried more weight when the armament arrangements were discussed. Above all however, the battleship, being the product of the navy's own design organization, would be built in a naval yard, and this offered him the opportunity of becoming directly involved to hurry construction. To Fisher's mind therefore, a radical battleship built to his own timelines to make a dramatic impact while demonstrating many of his key ideas was probably a valid and politically essential stepping stone along the route to the pure battlecruiser.

In the end however, this story is as much a salutary warning as to the unforeseen impact of human elements and changing strategic imperatives, as it is one of 
technological triumphs. There is no doubt for example that, with nothing else in evidence, the British public's attention focused on the Dreadnought and not, as Fisher had intended, on its proposed successor. To make matters worse, Fisher, through his vigorous promotion of the Dreadnought in order to overcome the resistance from the "small battleship types," seemed to all but the most informed to be committed to the design as an end in itself, and not as a stepping stone to something better. By the time the battlecruiser appeared, moreover, it seemed strangely out of step with the changing strategic circumstances. With France as a friend, and Russia temporarily out of the picture, there was only Germany to consider, and she was in no position to threaten Britain's global commerce in the way that France and Russia had. Worse still, the battlecruiser had lost its champion. Fisher by this time was fatally locked into the ever intensifying row over his handling of the reforms and, in particular, with an intensely personal dispute with the very influential Lord Charles Beresford over war plans. As a result, he was never free to lavish his enthusiasms on the battlecruiser in the way that he had done with Dreadnought. Finally there was the question of Fisher's over-confidence in his convictions. Further explanation was unwise and unnecessary, as the correct path was surely self evident. This part of his character did not serve him well. Fisher's own words on this are perhaps the best summation possible.

"The one great rule in life is NEVER EXPLAIN. Your Friends don't want an explanation. They believe in you. The friends who want an explanation ain't fit to be friends. Your enemies won't believe any explanation! I never in all my life have ever yet explained, and don't mean to." ${ }^{, 60}$

60 Found in a letter from Fisher to the journalist Arnold White in 1911, FGDN, 2: 388-389. 